\title{
EMPLOYMENT PROBABILITIES AND WORKFORCE DISTRIBUTION IN THE INDIAN MANUFACTURING SECTOR: A STATE-LEVEL ANALYSIS
}

\author{
Jadhav Chakradhar* and Arun Kumar Bairwa* \\ ${ }^{*}$ Corresponding Author, Centre for Economics and Social Studies, Hyderabad, India. \\ Email: chakrujadav@gmail.com \\ ** Indian Institute of Technology Indore, India. Email: arun.cuk@gmail.com
}

\begin{abstract}
Employment distribution disparities are preventing the Indian economy from achieving inclusive growth. The skewed distribution of employment is one of the reasons for the rising inequalities in the economy. In this regard, the present study analyses the employment probabilities of Indians working in the manufacturing sector. A binary logit model has been used on a pooled cross-sectional dataset of the fourth (201314) and fifth (2015-16) Employment and Unemployment Surveys (EUS). The study analyses four major attributes, namely castes (social categories), gender, location, and education. We analyze these attributes separately for all the 29 main Indian states, and find that caste and location are highly important deciding factors of employment probabilities in the manufacturing sector.
\end{abstract}

Keywords: Labour attributes; Employment inequalities; Employment probabilities; Logistic analysis; Indian manufacturing.

JEL Classifications: J71; R23; J15; J24.

Article history:

Received : February 13, 2020

Revised : March 30, 2020

Accepted : April 10, 2020

Available online : April 15, 2020

https://doi.org/10.21098/bemp.v23i1.1293 


\section{INTRODUCTION}

India is one of the fastest growing emerging economy in the world, but its employment conditions are highly unequal to disadvantaged groups (DFID, 2012; FICCI, 2014; IHD, 2014). The Seventh Five-Year Plan (1985-1990) of India identified employment as its key problem and explicitly aimed for productive employment (Papola, 2008). In this context, an extensive research has been done on the issues of employment, especially on employment generation, wage determination, and discriminations in the labour market (Aggarwal, 2016; Agrawal, 2014; Das \& Kalita, 2009; Madheswaran \& Attewell, 2007; Rani \& Unni, 2004). However, the issue of employment distribution has remained highly unexplored area of research. The skewed distribution in the employment creates employment inequalities, which further enhance poverty, social unrest, injustice, and inefficiencies in the economy (Labour Bureau, 2015). We hypothesize that these employment inequalities are attributed to the socioeconomic characteristics of individuals. In this regard, our study aims to explore inequalities in the Indian labour market by specifically focusing on the manufacturing sector.

We use the major socioeconomic characteristics (hereafter, labour attributes) of the Indian workforce to analyze employment inequalities. The major labour attributes of Indian workers are caste, gender, location, religion, language, and education. Existing studies have identified that firms decide the wage rate of employees on the basis of these labour attributes (Agrawal, 2014; Banerjee, 2016; Goldar \& Sadhukhan, 2015; Ramaswamy, 2012). However, existing studies ignored the impact of labour attributes on employment chances of the workers. Moreover, the issue of wage determination exists only if the people of disadvantaged groups are at least employed. Considering the nation's diversity, we hypothesize that people are discriminated while being hired for jobs. The identification of employment discrimination requires a detailed analysis of employment probabilities of the Indian workforce. In the aggregate employment of India, manufacturing sector employment has the highest potential for increasing inclusive and sustainable development (Amirapu \& Subramanian, 2015; Araujo, 2004; Sharma, 2013), and this is why we focus on the manufacturing sector. Furthermore, in order to capture the regional diversity and dynamics of employment inequalities, we analyze the employment probabilities of individuals for all the major Indian states as well as the aggregate Indian employment data.

We analyze the employment probabilities by using cross-sectional dataset of the fourth (2013-14) and fifth (2015-16) round of the EUS conducted by the Labour Bureau, Government of India. We extracted data of caste, gender, location, education, domicile state from the EUS. As per the research objective and nature of the dataset, the study employs binary logit models for empirical analysis. We check the robustness of our specifications using the Wald and likelihood ratio (LR) tests. The study finds extensive persistence of employment discrimination in the manufacturing sector. At the aggregate level, the most dominant labour attributes are caste and location. The state-level analysis shows variation in employment probabilities across states. The data shows that Northeast and South Indian states are more inclusive than North and West Indian states.

The empirical findings of the paper are briefly reported as follows. The overall manufacturing sector is broadly dominated by urban individuals. The states 
wherein rural individuals dominate are only few, and their contribution to total manufacturing output is miniscule. It is highly contradictory that India's $70 \%$ people live in rural areas but their employment chances in the manufacturing sector are considerably low. The states dominated by rural individuals have higher employment chances for females and lower caste individuals. The states where urban individuals are highly preferred to rural ones have higher contribution to the total manufacturing output. This is because the states wherein manufacturing concentrates in urban areas are likely to have the industries of higher capital intensity. Therefore, it is implicit that the industries with higher capital intensity are more productive than the labour intensive industries.

The study finds that manufacturing sector has higher potential to employ people with secondary and below secondary education. The share of the workforce with such level of educational attainment is higher in the lower castes. Despite this fact, the upper castes dominate the manufacturing sector, indicating that caste is more important than education as deciding factors of employment chances in the manufacturing sector. The level of discrimination is higher in the bigger Indian states, namely Maharashtra, Gujarat, Rajasthan, Tamil Nadu, Andhra Pradesh and Madhya Pradesh. Focusing on these states to reduce employment inequalities will have higher outcome, as these states dominate both manufacturing employment and output.

The next section reviews existing studies. Section III describes the data and presents the descriptive statistics. Section IV outlines the methodology. Section $\mathrm{V}$ presents the results, while section VI presents the conclusion and policy implications.

\section{LITERATURE REVIEW}

Diversity in employment distribution is an asset for businesses as well as for the economies. However, employment distribution has been highly exclusive and discriminatory throughout the world (Oxford, 2011). Developing nations tend to have most disparities in their total employment. However, the attributes of discrimination vary across countries. The main attributes affecting employment probabilities in both developed and developing nations are, among others, gender, education, health condition, age, ethnicity, family occupation, colour, habitation, caste or social category, nationality, culture, language, religion, family education (Agarwal, 2015; Aggarwal et al., 2011; Baah-Boateng, 2016; Bairwa et al., 2019; Bairwa and Sharma, 2019a, 2019b; Deshpande and Newman, 2007; Marelli and Vakulenko, 2016; Nilsson and Rubenson, 2014; Schioppa and Lupi, 2002).

Although employment opportunities vary with regards to labour attributes in each nation, the weaker sections of the society generally face lesser employment opportunities. The weaker sections of the society are the people of minority religion, indigenous and tribal people, females and third gender, people from the lower castes, illiterates, and rural people. For example, Italian youth from affluent families generally have easier access to matching jobs in the market, whereas their counterparts from low-income families struggle to even find a job (Schioppa and Lupi, 2002). This discrimination happens even if youth from both income classes have same education and skills. In India, poverty is highly correlated with caste 
and employment. The higher the caste level, the lower the level of poverty in that caste. This means people from lower castes tend to have higher incidences of multidimensional poverty (Thorat and Madheswaran, 2018). Owing to this, children from low-income families tend to enter the labour market earlier, which reduces their chances of attaining education and skills. The lower caste people have to enter the market early in order to earn their livelihood. Besides, they are unable to afford the expenses of higher education for their children. Conversely, children from high-income families tend to have lesser chances of entering the labour market early. This provides them adequate time to attain higher education and skills, which in turn increases their chances of getting jobs with higher remuneration (Kingdon, 1998). Hence, children from high-income families tend to out-earn their counterparts from low-income families in the long-run (Kingdon, 1998). In equilibrium, people from the lower castes tend to primarily cluster in underproductive, highly risky, and underpaid employment (Gang et al., 2012; IHD, 2014; Madheswaran and Attewell, 2007).

In this regard, Marelli and Vakulenko (2016) conclude that coming from a wealthier family background increases the probability of getting a job for first-time job seekers. Among the wealthy families, employment probabilities are highest for family-own businesses. In addition to this, first-time job seekers' probability of self-employment is most influenced by the father's employment status. This could be due to the argument that "People's ethnic and racial background may expose them to a variety of cultural and psychological factors that affect their risk-taking and management skills" (Hout and Rosen, 1999, p. 2). Similar to wealth status, the educational status of the family is essential when entering the job market. The parents with a strong education background educate their children in the best schools and offer a quality education. That is, family education is an influential factor determining the quality of education of an individual (Aggarwal et al., 2011; Kingdon, 1998). The level and quality of education greatly differ from family to family, wherein the Indian families mainly vary on the basis of castes. The families of lower caste are generally less educated. This reduces their chances to move out of menial jobs to highly productive jobs within or outside of the manufacturing sector (Aggarwal et al., 2011). Aside this, the returns to education is lower for the lower castes than it is for the upper castes. Even if the lower castes have equal education and competitive skills as the upper castes, they are paid less. The lower castes still largely work in less productive, risky, and vulnerable works (Madheswaran and Attewell, 2007). Discrimination and favouritism also exist on the basis of religion. Muslims have a greater tendency of being employed in underproductive, petty, and self-employment works (IHD, 2014). Moreover, the lower representation of the lower castes in entrepreneurship, non-menial occupations, and private jobs reduces their capability of using social networking to find matching jobs. This reduces the chances of employment for their children relative to those of their bosses (Bairwa and Sharma, 2019a; Cappellari and Tatsiramos, 2015; Deshpande and Newman, 2007).

The jobs being offered at factories and companies were limited to males till the 20th century, when India implemented the policies to increase women empowerment, and decrease sexual harassment and gender violence. In spite of 
this effort, females represented $22 \%$ of the total workforce compared to males who represented 78\% of the total workforce in 2015-16 (Labour Bureau, 2016). This niggling representation of females in the total Labour Force Participation (LFP) is attributable to numerous factors that affect their probability of employment. The Planning Commission of India (2012) argues that "women entitlements vary on the base of location but within various castes, communities, religion, geographies and development zones". The gender 'female' itself is considered inferior in India when it comes to education, employment or empowerments. Indian families generally favour sons over daughters with regards to education because the overall return to education is lower for daughters than for sons (Kingdon, 1998). This gender discrimination is also present in African nations, where Baah-Boateng (2016) finds that females have lesser chances than males in the market. In Italy, the female LFP is lower owing to the cultural and social stigma prevalent in the society (Schioppa and Lupi, 2002). Similar to education, gender, and caste, the 'location' attribute also plays a significant role in the probability of employment for the people.

This study broadly classifies location into rural and urban areas, and then analyses it for the selected Indian states. The distribution of employment in manufacturing firms varies across rural and urban areas. In most cases, the urban manufacturing industries are better than rural ones for employment generation (Ramaswamy, 2014). One of the primary reasons the rural areas perform worse in employment generation relative to the urban areas is the presence of comparatively lesser infrastructure and underdeveloped markets. In addition to the infrastructure endowments, firms decide their factory or business location by checking the local business regulations, land availability, labour laws, and tax rates (Agarwal, 2015). These differences in rules and regulations create regional disparities in employment distribution for the manufacturing sector. The regional inequalities increase labour migration from poor to rich areas, mainly from rural to urban areas. This further decreases the probability of employment for rural individuals (Dholakia, 1994). Situating manufacturing firms in rural areas increases employment and output, which in turn reduce the overall rural poverty (Panagariya, 2008). In a counter-argument, Thurik et al. (1999) state that the location factor will become irrelevant due to the increased usages of information and communication technologies, and telecommunication revolutions supported by faster globalization. This is highly relevant for the service sector but has limited applicability for the manufacturing sector. The manufacturing sector still requires considerable quality of physical infrastructure to build and operate its operational units. Therefore, location remains an essential factor when measuring regional inequalities (Fan and Sun, 2008). The next section briefly discusses the data source.

\section{DATA AND VARIABLE DESCRIPTION}

We use cross-sectional dataset comprising the fourth (2013-14) and fifth (2015-16) round of the EUS conducted by the Labour Bureau, Government of India. The questionnaire and the basic properties of the fourth and fifth EUS are similar, so both datasets have been amalgamated in order to create a pooled crosssectional dataset for the econometric estimations. The measurement unit of EUS 
is the sampled households and the individual members of these households. The EUS provides extensive social, economic and personal information of the surveyed households. We have extracted the information on individuals' castes (social category), gender, education, location (rural/urban), employment, and domicile state from the EUS dataset (see Tables 1 and 2). The EUS divides the castes into four broad social categories, namely SC, ST, OBC, and Others. The SC/ STs are marked as lower castes, OBCs denote middle castes, and Others denote upper castes. Our dataset includes only males and females, and excludes third gender. The education variable consists of total seven categories: 'illiterates or not literates', 'below primary literates', 'primary literates', 'upper primary literates', 'secondary literates', 'graduates', and 'postgraduates'. The location variable has two categories: 'rural' and 'urban'.

The sector or industry of employment is provided by the NIC - 2008 codes. A two-digit NIC code has been provided for each of the employed individuals, and indicates the sector, industry, and area of employment. All the people who have a two-digit NIC code, ranging from 10 to 33, are labelled as 'employed in the manufacturing sector' (ILO, 2019; MOSPI, 2008). All those for whom the NIC code is missing are marked as unemployed people in the present analysis, and are not considered for this analysis. Individuals who have an NIC code are part of the 'total employed workforce'. We perform state-level analysis and include 29 major Indian states in this analysis (see Appendix, Table B). Table 1 shows detailed descriptive statistics for all the variables used in the binary logit model estimations. The total sample size, the size of the active labour force, and the number of individuals working within the manufacturing sector are reported in Table 2. In an economy, share of 'total labour force' is always greater than 'total workforce', and the labour force consists of employed and unemployed people, whereas total workforce consists of only those who are employed in the economy (MOSPI, 2008).

Table 1 mirrors the basic descriptive statistics of the logistic regression. Table 2 shows that only $11 \%$ of the total workforce is employed in the Indian manufacturing sector (i.e. NIC 10 to 33), while the remainder of the employed population works in non-manufacturing sectors. Of the aggregate population, $71 \%$ hails from rural areas, and $56 \%$ of the total manufacturing workforce are from rural areas (Table 2).

Similarly, $47 \%$ of the Indian population is female, and their representation in the total Indian labour force is only $21 \%$ (Table 2). Caste statistics show that OBCs, Others, SCs, and STs comprise, respectively, $40 \%, 28 \%, 20 \%$, and $12 \%$ of the Indian population (Table 2). In terms of education, the majority of the Indian labour force is either illiterate (19\%) or has secondary-level (70\%) education (Table 1 and Table 2). In terms of education, illiterates retain the highest share of the total workforce at $19 \%$, while the lowest share is held by postgraduates at only $2.4 \%$ (Table 2 ). 


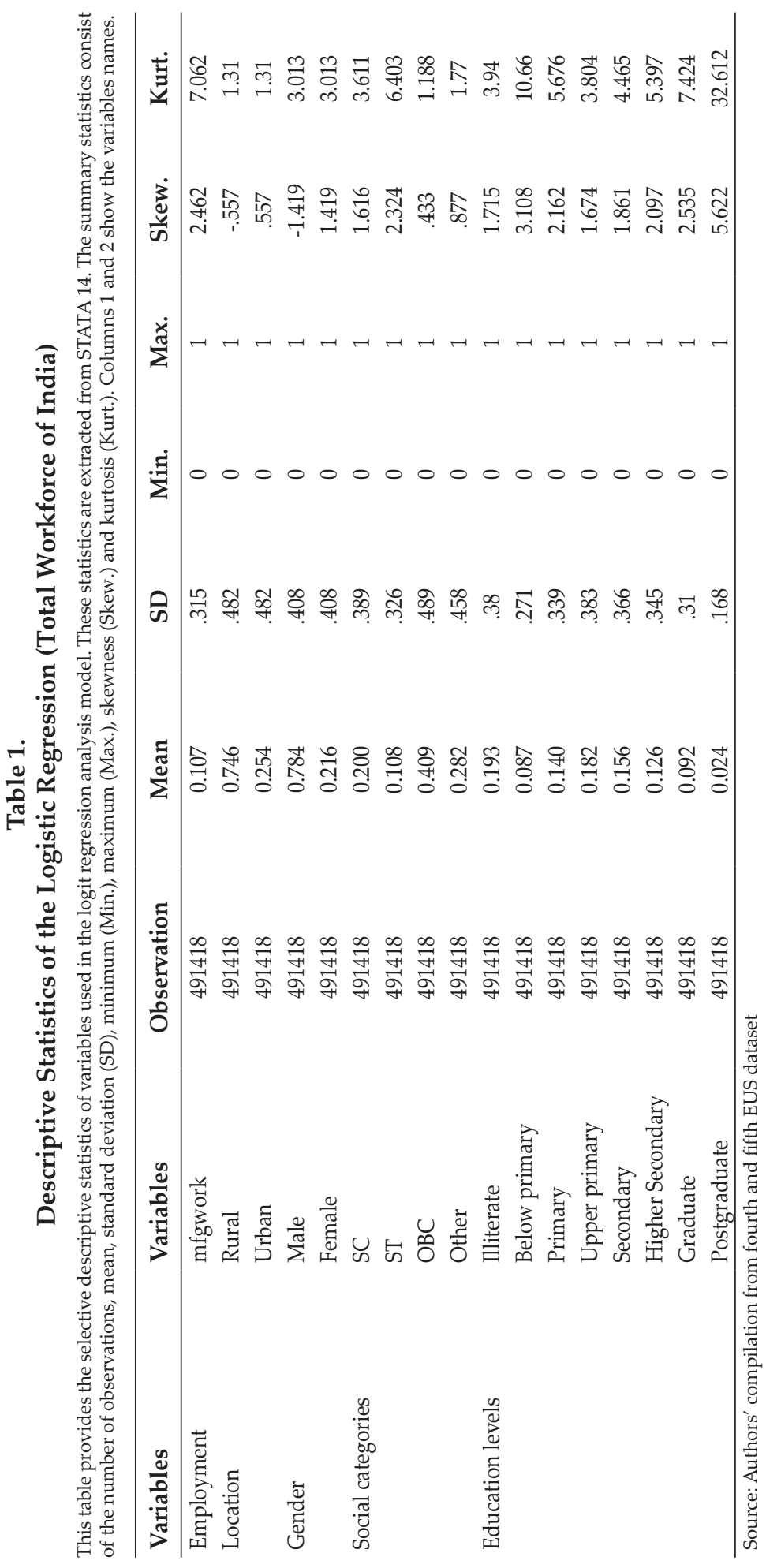




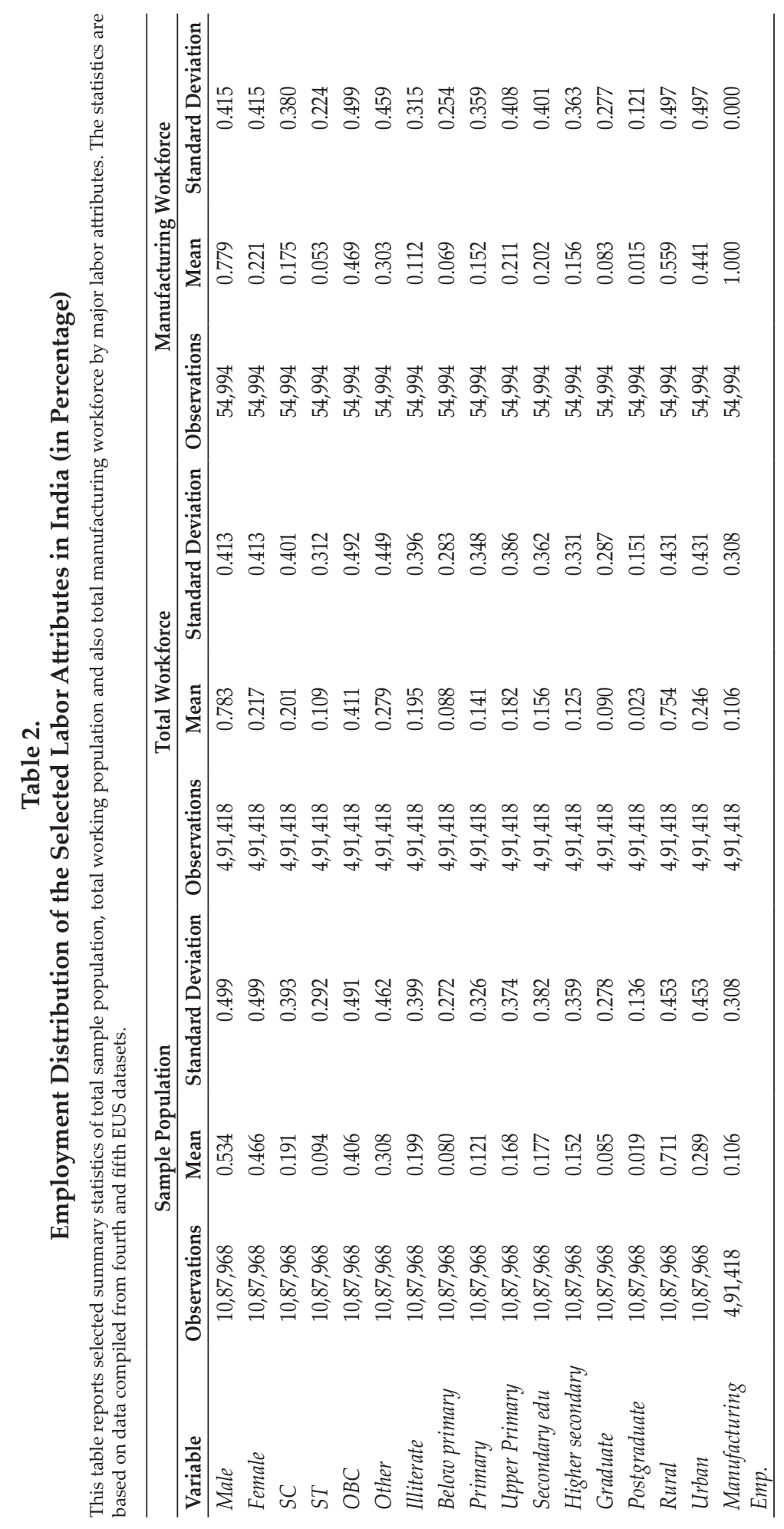




\section{METHODOLOGY}

Kong (2011) uses a multinomial probit model to analyse the impact of college reputation, course specialization, and gender on the employment and unemployment probabilities for Chinese graduate students. Hout and Rosen (1999) use a logit model and find that parental occupation plays an important role in employment of children. Kingdon (1998) employs a binary probit model to analyse Indian workers and concludes that girls are less motivated than boys to attain higher education. Schioppa and Lupi (2002) use a standard logit model to analyse product and labour market conditions among the youth in Italy and find that personal and family characteristics play an essential role in shaping careers. Schmidt and Strauss (1975) apply multiple logit models to certain personal characteristics and find that higher education decreases employment probabilities within the blue-collar sector. Marelli and Vakulenko (2016) use the Heckman probit model to analyse the role of individual and family characteristics on the risk of unemployment in Italy and Russia.

The main emphasis of this paper is to explore the probability of individuals' working in the manufacturing sector. We do this by using four labour attributes, namely level of education, caste, gender and location, and then estimating a binary choice model, wherein individuals employed in the manufacturing sector are assigned a value of one, and those employed in the non-manufacturing sector are assigned a value of zero. In what follows, we describe the binary choice model, its specification, and the precise properties of the dependent variable.

\section{A. Model Specification}

The latent variable in our model is dichotomous in nature, whereby individuals employed in the manufacturing sector are assigned a value of one and those employed in the non-manufacturing sector are assigned a value of zero. Hence, we estimate the probabilities of employment in the manufacturing sector by applying a binary choice model to the aggregate and state-level data. The binary choice regression model can be written as follows:

$$
y_{i}=\alpha_{o}+\sum_{j=1}^{k} \alpha_{j} X_{i j}+\varepsilon_{i}
$$

In Equation (1), $y_{i}$ is a qualitative response variable which takes the values 1 and 0 . It is defined as:

$$
y_{i}= \begin{cases}1 & \text { if } y_{i}>0 \\ 0 & \end{cases}
$$

The $X_{i j}$ is a vector of exogenous variables that influence $y_{i}$. Following Wooldridge (2003), the model takes the form:

$$
p_{i}=\operatorname{prob}\left(y_{i}=1\right)=\operatorname{prob}\left[\varepsilon_{i}>-\left(\alpha_{o}+\sum_{j=1}^{k} \alpha_{j} X_{i j}\right)\right]=1-F\left[-\left(\alpha_{o}+\sum_{j=1}^{k} \alpha_{j} X_{i j}\right)\right]
$$


In the Equation (3), $\mathrm{F}$ is the cumulative distribution function of $\varepsilon_{i}$. If the distribution of $\varepsilon_{i}$ is symmetric, and since, $1-F(-Z)=F(Z)$, we can write the Equation (3) as:

$$
p_{i}=F\left[-\left(\alpha_{o}+\sum_{j=1}^{k} \alpha_{j} X_{i j}\right)\right]
$$

Since $y_{i}$ depends on $x_{i j^{\prime}}$, we can write the likelihood function as:

$$
L=\prod_{y i=1} P_{i} \prod_{y i=0}\left(1-P_{i}\right)
$$

If the cumulative distribution of $\varepsilon_{i}$ is logistic, we have what is known as the logit model Maddala \& Lahiri (2009). In this case,

$$
F=\left(Z_{i}\right) \frac{\exp \left(Z_{i}\right)}{1+\exp \left(Z_{i}\right)}
$$

Hence, the

$$
\log \frac{F\left(Z_{i}\right)}{1-F\left(Z_{i}\right)}=Z_{i}
$$

For the logit model,

$$
\log \frac{P_{i}}{1-P_{i}}=\alpha_{o}+\sum_{j=1}^{k} \alpha_{j} X_{i j}
$$

The left-hand side of Equation (8) is the log-odds ratio, and it is a linear function of the explanatory variables.

\section{B. Empirical Approach}

In order to obtain the probability of employment in the manufacturing sector in India, we estimate two binary choice models, which are similar to the studies of Schmidt and Strauss (1975) and Marelli and Vakulenko (2016). That is, we estimate the following models:

$$
y_{i}=\alpha_{o}+\sum_{j=1}^{k} \alpha_{j} X_{i j}+\varepsilon_{i}
$$


In Equation (9), $a_{j}$ represents the coefficients of the independent variables $x_{i j}$ in the model. Specifically, we estimate two forms of Equation (9) as follows:

$$
\begin{aligned}
Y_{i}\left(Y_{i}=1 \mid 0\right)= & \alpha_{0}+\alpha_{1} \mathrm{X}_{1}+\alpha_{2} \mathrm{X}_{2}+\alpha_{3} \mathrm{X}_{3}+\alpha_{4} \mathrm{X}_{4}+\alpha_{5} \mathrm{X}_{5}+\alpha_{6} \mathrm{X}_{6}+\alpha_{7} \mathrm{X}_{7}+ \\
& \alpha_{8} \mathrm{X}_{8}+\alpha_{9} \mathrm{X}_{9}+\alpha_{10} \mathrm{X}_{10}+\alpha_{11} \mathrm{X}_{11}+\alpha_{12} \mathrm{X}_{12}+u_{i j} \\
Y_{i}\left(Y_{i}=1 \mid 0\right)= & \alpha_{0}+\alpha_{1} \mathrm{X}_{1}+\alpha_{2} \mathrm{X}_{2}+\alpha_{3} \mathrm{X}_{3}+\alpha_{4} \mathrm{X}_{4}+\alpha_{5} \mathrm{X}_{5}+u_{i j}
\end{aligned}
$$

In Equation (10), $Y_{i}$ represents 'manufacturing employment', $a_{0}$ is a constant, $X_{1}$ is 'female gender', $X_{2}$ is 'rural location', $X_{3}$ is 'scheduled caste', $X_{4}$ is 'scheduled tribes', $X_{5}$ is 'other backward castes'. The variables $X_{6}, X_{7}, X_{8}, X_{9}, X_{10}, X_{11}$ and $X_{12}$ represent 'not literate', 'below primary education', 'primary education', 'upper primary education', 'secondary education', 'higher secondary education', and 'graduate education', respectively (see Appendix, Table A), $u_{i j}$ and is the error term. The main independent variables in Equation (10) are 'other castes', 'urban location', 'male gender', and 'postgraduate education'.

In Equation 11, $Y_{i}$ represents 'manufacturing employment', $a_{0}$ is a constant, $X_{1}$ denotes 'castes', $X_{2}$ denotes 'rural location', $X_{3}$ denotes 'female gender', $X_{4}$ denotes 'education', $u_{i j}$ and is the error term. $X_{1}$ and $X_{4}$ are, respectively, the caste and education and are ordinal variables in Equation (11). ${ }^{1}$ The benchmark categories are males for gender and rural areas for location.

\section{ECONOMETRIC ESTIMATION AND DISCUSSION}

Estimates of Equations (10) and (11) are reported in Tables 3 and 4, respectively. In total, we estimate 30 regressions: 29 for the major Indian states ${ }^{2}$ and one for the entire India. The last rows of Tables 3 and 4 show the regressions for the aggregate Indian data, excluding the union territories. The sample size of the EUS data

1 Caste and education are considered as ordinal variables in Equation (11). Here, education is already an ordinal variable as it varies from 'not literate' to 'postgraduate'. Illiterates are assigned a value of 0 , below primary literates are assigned 1 , and this process goes on till 7 , where 7 represents postgraduate education. This is not the case for the caste categories. From both a theoretical and ethical perspective, an individual should never be considered inferior or superior on the basis of their caste. Numerous science and social science studies have demonstrated this, and the Indian Constitution strongly discourages measuring capabilities on the basis of caste categorization. However, in practice, the Indian society is vastly different from these idealistic suppositions. The majority of Indians (mainly Hindus) have a particular social category, caste, and sub-caste (Ilaiah, 1996). Each caste is placed both above and below another castes (Ambedkar, 1944). In brief, the highest caste is the Brahmin caste (Others category) and the lowest caste is Shudra (Scheduled Castes) (Dom, 1999). In between are the OBCs which come below the upper castes, but are above the SC, (Ilaiah, 1996). STs are castes which are not part of Hindu society (but are still listed within the Hindu castes) (Agrawal, 2014); they are economically and socially vulnerable as is the case of the SCs. Comparatively, the SCs are slightly ahead of the STs in social and economic progression due to their living in mainstream society, whereas the STs still predominantly live in forests and tribal areas. Therefore, the descending order of the castes as per social and economic parameters is: Others, OBCs, SCs, and then STs (Walters, 2019, p. 3). We assign one to STs, two to SCs, three to OBCs, and four to Others in this study.

2 In this study, the 'major Indian states' of India are the states which are among the top ten states in terms of total employment, output, geographical area, and population. See Figure 6. 
varies in proportion to the population of the states-therefore, small states are represented by a smaller proportion within the total EUS sample (Tables 3 and 4). Total observations for each state are reported in Tables 3 and 4 . Full names of the states are reported in Appendix Table B, and the remaining tables use only abbreviations. The regression coefficients are interpreted with interactions and descriptive statistics derived from the fourth and fifth EUS data compilations. However, all descriptive statistics used for the discussion, other than Tables 1 and 2 , are not provided here due to space constraints. The descriptive statistics used throughout the study might vary by $\pm 2 \%$ from the official reports of Government of India as we have pooled two rounds of datasets. All the logistic estimations and descriptive statistics have been generated using Stata 14 software.

\section{A. Model Robustness}

Tables 3 and 4 are compiled after checking regression robustness, and results of the robustness tests are reported in both the tables. We first checked for multicollinearity among the predictors-i.e., the labour attributes (caste, gender, location, and education). We found no predictor to be highly correlated with another predictor, and the maximum collinearity among predictors was -0.53 between OBCs and Other castes. Further, we used the LR and Wald tests to test the null hypothesis that the coefficients of all the predictors are equal to zero (Cameron and Trivedi, 2010), and rejected the null hypothesis for all the regressions. The statistics of both the LR and Wald tests are reported in Tables 3 and 4. The inferences derived from the logistic regressions are discussed in the next section.

\section{B. Discussion}

Both models (i.e. Tables 3 and 4) indicate that labour attributes play a major role in determining the employment probabilities of the workforce employed in the Indian manufacturing sector. One of the major contributions of this study is that our results indicate that all the selected Indian states highly vary from one another with respect to the labour attributes. The overall analysis shows that bigger states have lesser diversity in their total manufacturing employment. Conversely, the smaller states (especially the Northeastern states) are more inclusive than bigger states in terms of employing females, lower castes, and rural workers.

Review of existing literature shows that, in comparison to agriculture and service sector, females have least employment probabilities in the manufacturing sector (Bairwa and Sharma, 2019a), and that the largest share of female workforce is concentrated in the agriculture and service sectors. Further, the industries in which females have highest employment probabilities are the industries of 'tobacco products's, 'textiles', 'wearing apparel', 'computer, electronics and optical

\footnotetext{
3 The workers of tobacco industry are involved in a wide range of activities associated with tobacco, such as planting, weeding and maintaining beds and picking of tobacco leaves, and removing the leaves after drying.
} 
products', and 'other transport equipment'4 (Bairwa et al., 2019). All the other 23 manufacturing industries, except the above-listed six, have higher dominance of males. Among all the remaining 17 manufacturing industries, females have least employment chances in the industries of 'repair and installation of machinery and equipment', 'furniture', 'machinery and equipment', 'basic metals', and 'coke and refined petroleum products' (Bairwa et al., 2019).

In the total workforce of India, females represent only $22 \%$ share against the $78 \%$ share of males (Table 1). This figures highly vary across the Indian states, as indicated by the logistic estimates. The estimates in Tables 3 and 4 show that females have higher likelihood of getting employed in the manufacturing sector; however, this is subject to further analysis. The odd ratios of females are higher because their share is higher in the manufacturing workforce, but lower in the total workforce. The proportion of females in the total workforce is only $29 \%$, but their share in total manufacturing workforce is $73 \%$ in the state of Manipur. The lower labour force participation rate of females in almost all the states is the main reason behind this problem. In order to overcome this issue, the coefficients of each labour attributes (especially gender) are interpreted with respect to the descriptive statistics. The coefficient of females in Table 3 shows higher chances of female employment if higher share of 'total employed workforce' is engaged in 'manufacturing employment'. In other words, females will have higher employment probabilities (in comparison to males) if larger part of the 'total employed workforce' is employed in the manufacturing sector.

Accordingly, Table 3 shows that females have highest probabilities of manufacturing employment in Manipur, Jammu Kashmir, West Bengal, Telangana, and Kerala. The share of females in the total manufacturing employment of these states is 73\% (Manipur), 24\% (Jammu Kashmir), 26\% (West Bengal), 50\% (Telangana), and $40 \%$ (Kerala). When compared with all the states, females of Manipur have the highest employment chances relative to their male counterparts. Here, females are just $29 \%$ of the total employed workforce; but their share in total manufacturing workforce is $73 \%$. This state is highly favorable for females to get manufacturing sector jobs. Conversely, the males consist of $71 \%$ of total workforce of Manipur, but their share is only $27 \%$ in the total manufacturing workforce. Manipur has the higher share of females in manufacturing because it has better developed textile industries. Out of the total employed workforce of the textile industry, only 1\% are males compared with $99 \%$ females. From the total manufacturing employment of Manipur, $54 \%$ are employed in the textile industry. This affirms the finding of Bairwa et al. (2019) that the textile industry has higher employment chances for females over males. Other industries, such as apparel $(17 \%)$ and food products $(9 \%)$ also generate higher employment for females in manufacturing in Manipur. At the aggregate level, the apparel industry inclusively employs both males and females, whereas the furniture industry mainly employs males (Bairwa et al., 2019).

${ }^{4}$ Manufacturing of 'other transport equipment' consists of 'building of ships and boats', 'railway locomotives and rolling stocks', 'air and spacecraft and related machinery', and 'military fighting vehicles'. 
Similarly, females consist of $12 \%$ share in the total workforce of Jammu Kashmir, but their share is $24 \%$ in the total manufacturing workforce. The number of observations for Jammu Kashmir are miniscule, so further investigation could not be done for this state. In West Bengal, 16\% of the workforce are females, but females' share in total manufacturing workforce is $26 \%$. Females have larger share than males in in three industries of West Bengal, namely textiles, apparels, and paper and paper products. Another important state for better female employment is Telangana (Table 3). It has 38\% share of females in its total employed workforce, but the share of females in total manufacturing employment is $51 \%$. Conversely, males retain $62 \%$ share in total employed workforce, but consists only of $50 \%$ share in total manufacturing employment. This implies that, though females have lesser share in the total employed workforce, a higher share of them in the total employed labour force is employed in the manufacturing sector. Bairwa et al. (2019) found that females have higher employment probabilities in industries of 'tobacco products' 5 and 'wearing apparels' in Telangana. Overall, the maximum share of total employment in Telangana is in the industries of tobacco products $(35 \%)$, wearing apparels $(17 \%)$, and food products $(7 \%)$. These are also the industries that highly favor females over males for manufacturing employment (Bairwa et al., 2019). We found that Tripura, Assam, Kerala, and Karnataka also have higher employment chances for females (Table 3), and these states have a significant share of 'tobacco products', 'textiles', and 'apparel' industries in their total manufacturing employment. In the case of Assam, the industries dominated by females retain higher share in the total manufacturing employment. Thus, the probability of finding manufacturing employment is higher for females in Assam. The maximum employment in Assam is in furniture (18\%), textiles (16\%), and apparels (13\%) industries.

The states in which females have higher employment probabilities contribute less to output and employment. Most of the manufacturing employment and output are retained by the states that mainly prefer males to females for employment. The major states among them are Meghalaya, Gujarat, Punjab, Uttarakhand, Himachal Pradesh, Maharashtra, Haryana, and Chattisgarh (Tables 3 and 4). The share of females in their total manufacturing employment is only 28\% (Meghalaya), 12\% (Gujarat), 9\% (Punjab), 13\% (Uttarakhand), 15\% (Himachal Pradesh) 19\% (Maharashtra) 7\% (Haryana), and 21\% (Chhattisgarh). The possible reason behind this could be attributable to the dominance of certain industries and their strong preference for males in these states. Specifically, the industries with the highest employment chances for males at the country level are 'repair and installation of machinery and equipment', 'furniture', 'machinery and equipment', and 'basic metals' (Bairwa et al., 2019). If a state has higher share of these industries in its manufacturing sector, then it is highly likely for that state to prefer males to females for manufacturing employment. The reverse is true for states that have higher share of industries with strong preference for females. For instance, Meghalaya has the least employment probabilities for females (Table 3) because this state has considerably lesser share of industries that mainly employ females. Extensive industry-level details of the workforce dynamics cannot be provided for this state due to insufficient sample size. 
After Meghalaya, Gujarat provides females the least chance in manufacturing employment (Table 3). Note that Gujarat is one of the leading states in terms of manufacturing output and employment. However, industries that usually prefer females are dominated by males in this state. For example, the overall textile manufacturing sector of Gujarat employs 89\% males compared with 11\% females. The other industries in which males are highly preferred to females in Gujarat are 'machinery and equipment', 'electrical equipment', 'chemical and chemical products', 'pharmaceuticals, medicinal chemical and botanical products', and 'other manufacturing' ${ }^{5}$. Also, Gujarat's maximum manufacturing employment is generated in other manufacturing (23\%), textiles $(16 \%)$, and apparels $(15 \%)$ industries. Additionally, there is a trend that manufacturing industries that require higher manual and heavy work are dominated by males (Bairwa and Sharma, 2019a). Broadly, there are only few states that prefer females to males for employment in the manufacturing sector. Even among females, the lower caste females face worse conditions in the labour market. The lower caste females face double discrimination - the first is on the basis of gender and the second is on the basis of caste (Bairwa et al., 2019). The caste discrimination widely exists among males as well.

The results show that the states with the highest levels of caste discrimination regarding employment choices are Manipur, Meghalaya, Chhattisgarh, West Bengal, and Telangana (Tables 3 and 4). The utmost discrimination is in the state of Manipur. In Manipur, the Other/OBC ${ }^{6}$ and SC/ST ${ }^{7}$ category consists $62 \%$ and $38 \%$ of the total workforce. From this total employed workforce of Other/OBCs, $88 \%$ are employed in the manufacturing sector. Despite having significant share in the total employed workforce, the SC/STs retain only $12 \%$ share in the total manufacturing employment. One of the reasons could be the high dominance of Other/OBCs in the textile industry. The OBC/Others retain $86 \%$ of all the textiles industry jobs, whereas the SC/STs retain only $14 \%$ jobs. However, this textile industry of Manipur makes this state the most favorable for female employment. From all the textile sector jobs of Manipur, $99 \%$ are retained by female workers. Since the highest share of textiles jobs is retained by OBC/Other category, it is obvious that most of the females working in the textile industry of Manipur belong to the $\mathrm{OBC} /$ Other category. Aside Manipur, Meghalaya is another state that strongly prefers upper castes to lower castes for manufacturing employment. The SC/STs retain $83 \%$ share in the total manufacturing in this state, despite having $87 \%$ share in the total population and $89 \%$ share in the total employed workforce. Conversely, the OBC/Others consists of only $11 \%$ share in the total employed workforce, but retain $17 \%$ of the jobs in the manufacturing sector. The STs are the least dominant of the castes in the manufacturing employment of Meghalaya. Broadly, the STs dominate the 'food products', 'wood and products of wood and cork', 'chemical

5 NIC-2008 classifies 'other manufacturing' in the Division 32. The three-digit NIC code for this industry is 321. It mainly deals with the manufacturing of 'jewelry and related articles', 'musical instruments', 'sports goods', 'games and toys', 'medical and dental instruments', etc.

6 'Other/OBC' represents the combination of the Other and OBC categories. These are higher/upper castes.

7 'SC/ST' represents the combination of the Scheduled Castes and Scheduled Tribes categories. 
and chemical products', and 'rubber and plastic products' industries (Bairwa et al., 2019).

Chattisgarh, West Bengal, and Telangana also show high preference for the upper castes (Tables 3 and 4). The reason behind this is that these states have high share of the OBC/Other category in their total population. The OBC has $45 \%$ and $52 \%$ share in the total population of Chattisgarh and Telangana, respectively, while, in West Bengal, Others has 53\% share in the total population. Out of the 23 major manufacturing industries at the country level, the Other category dominates 10 manufacturing industries, and these are the industries with highest capital- and skill-intensity requirements (Bairwa et al., 2019). Therefore, except for Kerala and Goa, all states with higher share of OBC/Other in their total population have higher dominance of upper castes in their total manufacturing sector. However, the same is not true for states in which SC/STs have higher share in the total population. Except for Arunachal Pradesh, the states in which lower castes have higher share in total population are also dominated by higher castes. This shows that higher castes still dominate lower castes in manufacturing sector employment.

The interesting finding from our study is that out of the 29 states, Arunachal Pradesh has the least employment discrimination for the lower castes. However, the estimates of this state are not very robust and significant due to lower sample size. Apart from Arunachal Pradesh, Table 4 shows that Assam and Kerala also have low caste discrimination. These states have slightly better conditions compared to other states with regards to inclusive employment in the manufacturing sector of all the castes. Assam has better employment opportunities for SCs and OBCs, whereas Kerala has better employment opportunities for STs and OBCs. Compared to the Others caste, OBCs have high employment opportunities in almost all the states, SCs have moderate employment opportunities in most of all the states, and STs do not have high employment opportunities in all the states but Goa, Karnataka, and Uttar Pradesh.

The caste and gender attributes work simultaneously with the location factor. The possible reason is that the lower caste and the female gender population mostly reside in rural areas. At the aggregate level, the manufacturing workforce in rural areas has better sex ratio than that of urban areas (Bairwa and Sharma, 2019a). Similarly, when location is studied alongside caste, we found that employment distribution of overall rural manufacturing jobs is highly inclusive for lower castes. This means the employment chances of lower castes are higher if a particular manufacturing industry prefers to employ rural individuals. However, at the aggregate level, the manufacturing sector prefers to employ urban people (Bairwa and Sharma, 2019a). Of the 23 major manufacturing industries, 15 prefer urban to rural individuals (Bairwa et al., 2019). Therefore, most of the Indian manufacturing industries prefer urban individuals, and industries preferring urban individuals tend to have higher bias toward lower castes, except for industries in Arunachal Pradesh state.

The manufacturing sector of Meghalaya, Chhattisgarh, Haryana, Maharashtra, and Punjab Gujarat have the least preference for rural individuals to urban individuals (Tables 3 and 4). The share of rural workers in the manufacturing sector of these states is 52\% (Meghalaya), 49\% (Chattisgarh), 51\% (Haryana), 33\% (Maharashtra) and 41\% (Punjab). The logit model shows that Meghalaya ranks 


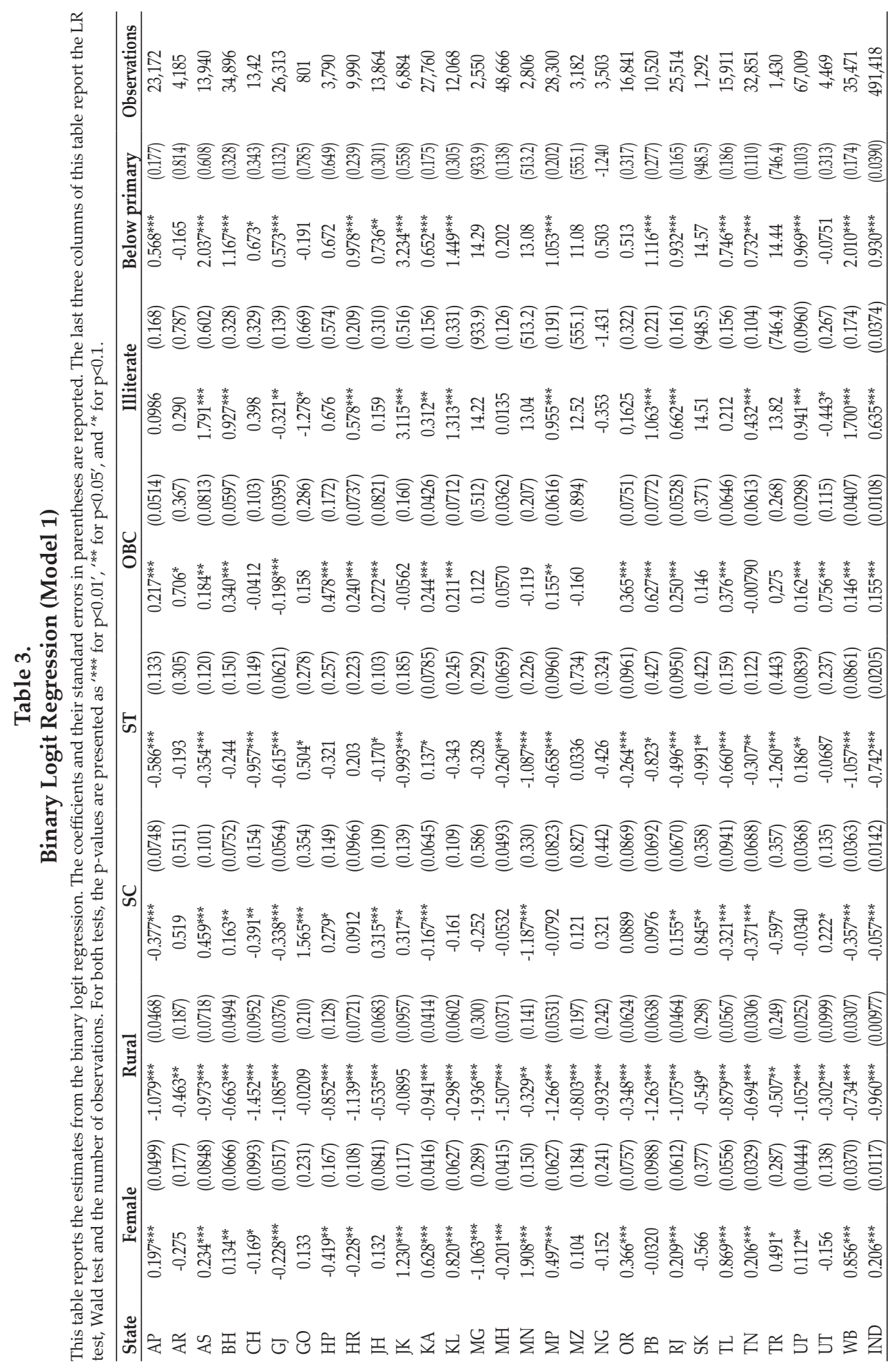




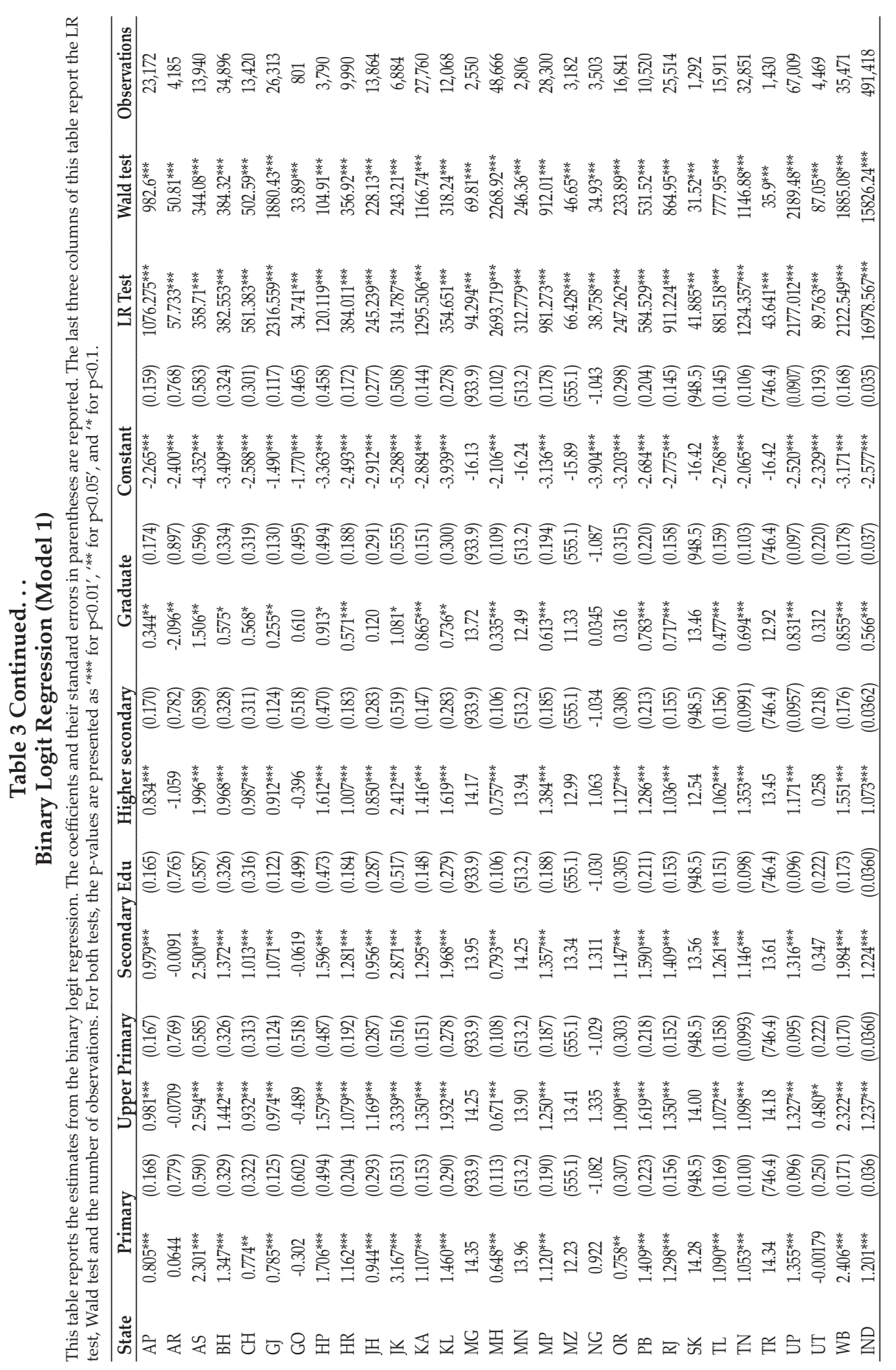




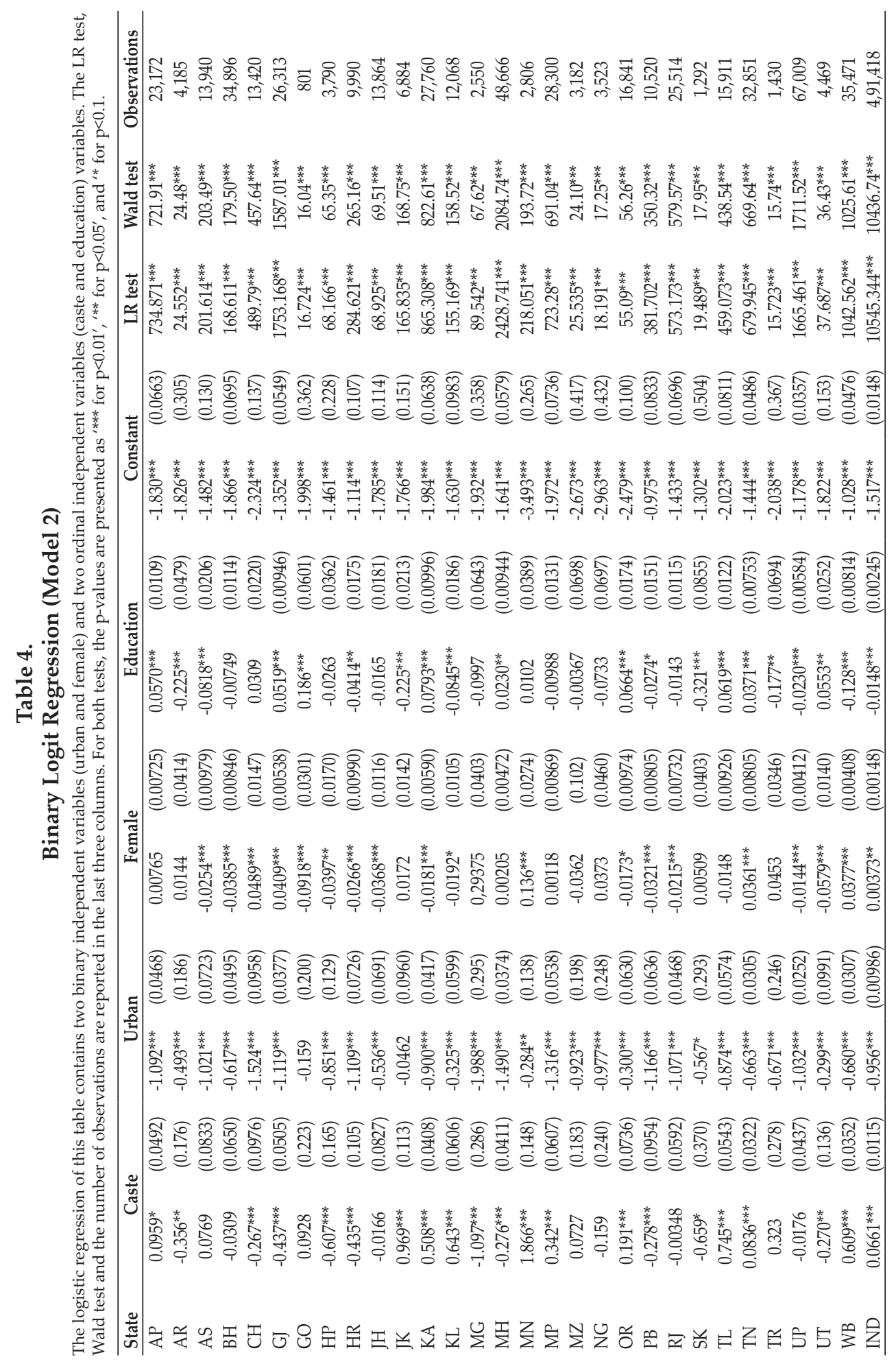


highest in terms of discrimination against rural individuals. However, further analysis shows that $82 \%$ share of the total employed workforce of Bihar are based in rural areas, but the share of rural people in the total manufacturing workforce is only $52 \%$. Conversely, urban individuals are only $18 \%$ of the total employed workforce, but consists $48 \%$ share in the total manufacturing workforce. In the total manufacturing workforce of Meghalaya, the majority of the people are employed in the furniture (45\%), apparel (26\%), and 'wood and products of wood' $(13 \%)$ industries. These statistics are similar to those recorded for Chhattisgarh, Haryana, Maharashtra, Punjab, and Gujarat, and to a lesser extent Meghalaya. Chhattisgarh is an industrial state and its rural workforce mainly engaged only in the traditional industries requiring less capital. The Chhattisgarh industries that employ more rural workers than urban workers are two, namely 'other nonmetallic mineral products' and 'textiles'. This Indian state is different compared with others because a larger part of its urban manufacturing workforce is employed in the manufacturing industries of 'basic metals', 'other manufacturing', and "fabricated metal products, except machinery and equipment". The characteristics of industrial concentration of Chattisgarh are similar to those of Jharkhand.

The overall the manufacturing sector prefers urban to rural workers (Bairwa et al., 2019; Bairwa and Sharma, 2019a), so the states where rural people have higher employment chances are only few in number. The results from the binary logit models show that Kerala, Orissa, Uttarakhand, Punjab, and Manipur states have slightly better opportunities for rural people; although, they also prefer urban individuals for manufacturing employment (Tables 3 and 4). The share of rural workforce in the total manufacturing workforce of these states is $58 \%$ (Kerala), $81 \%$ (Orissa), 64\% (Uttarakhand), (41\%) Punjab, and 62\% (Manipur). These states have inclusive employment opportunities for females and the lower castes. However, the total population of these states represent minimal share of the total population of India. The major states of India have higher employment chances for only urban people in manufacturing. Further, we found that the industries that employ more rural individuals are those that mainly employ the lower castes, females, and less-educated people. In addition to caste, gender, and location, education is an important determinant of the employment probabilities of workers across the Indian states.

Bairwa \& Sharma (2019a) shows that education is least important for the agriculture sector, moderately ${ }^{8}$ important for the manufacturing sector, and highly important for the service sector employment. Similarly, Bairwa et al., (2019) found that education is highly important for employment in capital-intensive manufacturing industries, whereas it is least or moderately important for labourintensive manufacturing industries. The industries with strong preference towards the highly educated or skilled workers are 'pharmaceuticals, medicinal, chemical, and botanical products', 'computer, electronic, and optical products', 'machinery and equipment', 'printing and reproduction of recorded media', and 'electrical equipment' industries (Bairwa et al., 2019, p. 11). However, the share of capital-

8 Moderately important means neither totally illiterate nor highly qualified. People with primary and secondary level of education are considered here. 
intensive manufacturing industries in the Indian economy is minuscule, so the demand for skilled workers is lower than that of unskilled workers. The logit regression shows that the chances of getting employed in the manufacturing sector decreases with increases in the level of education. Specifically, the employment chances in manufacturing increases until the level of education increases from 'not literate' to 'secondary school' literate, and after that employment chances starts declining (Bairwa and Sharma, 2019b).

The chances of entering into manufacturing employment is positively related with increases in education level for only few states: Goa, Karnataka, Orissa, Maharashtra, and Andhra Pradesh (Table 4). We found these states, along with other states, to have higher employment chances for the less-educated people, when compared with postgraduates. Maharashtra and Andhra Pradesh have low preference for educated individuals, yet they have a remarkably higher share of graduates and postgraduates in their total manufacturing employment. There are only few states where postgraduates have more than $2 \%$ share in the total manufacturing workforce; such states are Goa (5.2\%), Uttaranchal (5.1\%), Nagaland (2.9\%), Maharashtra (2.5\%), and Haryana (2.3\%). Except for Maharashtra and Haryana, all of these Indian states are minuscule in both total workforce and manufacturing workforce. The states where 'not literates' have highest share in the total manufacturing employment are Jammu Kashmir (25\%), Telangana (24\%), Arunachal Pradesh (20\%), Bihar (19\%), Madhya Pradesh (16\%), Andhra Pradesh (16\%), and Uttar Pradesh (16\%). These states represent 31\% of the Indian total manufacturing workforce, and they are the major states of India in terms of geographical area, population, and contribution to total output. This indicates that the Indian manufacturing sector is almost fully labour-intensive. In the total manufacturing employment of India, Uttar Pradesh (14\%) provides the highest employment, followed by Tamil Nadu (12\%), West Bengal (12\%), Maharashtra $(8 \%)$, Gujarat (8\%), and Karnataka (6\%). Among these states, Uttar Pradesh, West Bengal, and Tamil Nadu provide the highest employment chances for educated people, whereas Karnataka and Maharashtra prefer employing people with secondary level education. This further affirms that the Indian manufacturing sector is labour-intensive.

\section{CONCLUSION AND POLICY IMPLICATIONS}

This study used binary logit models to analyze the determinants of employment probabilities in the Indian manufacturing sector. Considering the high diversity of the Indian subcontinent, we used 29 major Indian states for the analysis, aside analyzing the aggregate data. The study focused on four major attributes of workers in the manufacturing sector, namely castes, gender, education and location. We found high level of diversity across Indian states in terms of employment probabilities.

Overall, we found that location and castes are the most important attributes influencing employment probabilities in the Indian manufacturing sector. Rural workers dominate manufacturing employment only in states that contribute less to the total manufacturing output of India. Coincidently, the states with strong preference for rural workers provide higher chances of employment for the lower 
castes and females, and this is attributable to the lower castes being mainly rural dwellers. Females have higher manufacturing employment share in these states mainly because the industries prefer rural female workers. In most of the Indian states, the manufacturing sector highly prefers urban to rural people, and these states generate most of the manufacturing employment and output. This confirms that manufacturing sector is biased towards rural individuals. This is unfortunate given that the manufacturing sector has a great potential relative to the primary and tertiary sectors to generate employment for rural individuals.

We found that the Indian manufacturing sector is discriminatory towards the lower castes (SC/STs) for employment. Few states, Arunachal Pradesh, Assam, and Kerala, provide better employment chances for the lower castes. Even in the states in which the share of SC/STs is higher than that of OBC/Other, the upper castes have higher employment probabilities in manufacturing sector. The states in which the lower castes have lower chances in manufacturing employment, manufacturing industries contribute negligibly to the aggregate output and employment. Conversely, the highly capital and skill intensive industries mostly employ the upper caste individuals. The location and caste factors are highly related with the gender attribute. We found that females from the lower castes and rural areas are the most discriminated in manufacturing employment.

Our logistic estimates for gender showed that males and females have equal employment chances in the Indian manufacturing sector. However, additional analysis showed that the manufacturing sector highly prefers males to females. The industry-level analysis of employment distribution of males and females showed that females are limited only in few of the manufacturing industries, and this trend is constant across the states. This is consistent with the traditional and conservative beliefs of the Indian society regarding female employment in manufacturing sector. Classifying industries by the nature of work, we found that males dominate high heavy-manual, skill-intensive, and outdoor industries, while females dominate textiles, tobacco, and apparels industries. Females are generally discriminated in across states, but they tend to have higher employment chances in the labour-intensive industries with low educational requirement.

Employment chances in labour and capital-intensive manufacturing industries are highly correlated with the level of education. More educated workers tend to be employed in the capital-intensive manufacturing sectors. Given that the Indian manufacturing sector is labour-intensive, low educated or illiterates dominate the manufacturing employment. We found that education is the least important compared with the caste, location, and gender of an individual. People with primary (including upper and lower primary) and secondary (including higher secondary and diploma) have highest employment chances in the Indian manufacturing sector. As the level of education increases, the chances of employment in the manufacturing sector declines.

The employment distribution in the Indian manufacturing sector is highly biased in all the states. The negligence of rural people, females and lower castes poses a serious threat to India's aim of achieving inclusive growth. To level the playing field the states should provide employment quotas/reservations in the manufacturing sector for these excluded members of the society (or weaker 
sections). ${ }^{9}$ The governments should focus on the bigger Indian states because we found these states to practice higher discrimination towards the weaker sections. Also, these states generally have high potential to than the smaller states to generate additional manufacturing employment for the weaker sections.

Skill enhancement training and apprenticeship programmes should mainly target the weaker sections of the society, and these programmes should be linked to the manufacturing industries. As part of corporate social responsibility, companies in the manufacturing industries should be encouraged by the government to promote rural startups, particularly those engineered by the disadvantaged. The people of weaker sections of the society mainly engage in the unorganised manufacturing industries. The states should implement additional labour and industrial reforms to transform these industries into organised manufacturing industries. This will certainly motivate the disadvantaged sections to move to the better-paid, capital and skill intensive manufacturing sector jobs. Additionally, a Labour Socials Diversity Index (LSDI) should be developed to measure the representation of the disadvantaged groups in the manufacturing sector. The LSDI index should be published for all the Indian states and all the major manufacturing industries. Based on the performance of industries on the LSDI index, the government should incentivize the firms with tax credit and wage subsidies.

\section{REFERENCES}

Agarwal, A. (2015), An examination of the Determinants of Employment Center Growth: Do Local Policies Play A Role? Journal of Urban Affairs, 37, 192-206.

Aggarwal, A., Johnes, G., Freguglia, R.S. and Spricigo, G. (2011), Education and Labour Market Outcomes: Evidence from India, Working Paper No. 615663, Lancaster University Management School, Economics Department, United Kingdom, available at: https://www.lancaster.ac.uk/media/lancasteruniversity/content-assets/documents/lums/economics/working-papers/ EducationLabouMarketIndia.pdf (accessed 30 November 2016).

Aggarwal, A. (2016). Growth, Employment and Structural Change: Punjab Versus 16 Major States of India. In L. Singh \& N. Singh (Eds.), Economic Transformation of a Developing Economy (pp. 229-249). Springer Singapore. https://doi.org/10.1007/978-981-10-0197-0_11

Agrawal, T. (2014), Gender and Caste-Based Wage Discrimination in India: Some Recent Evidence. Journal for Labour Market Research, 47, 329-340.

Ambedkar, B.R. (1944), Annihilation of Caste: With a Reply to Mahatma Gandhi, 2nd ed., Higher \& Technical Education Department, Government of Maharashtra, Mumbai, available at: https://www.worldcat.org/title/annihilation-of-castewith-a-reply-to-mahatma-gandhi/oclc/950889730\&referer=brief_results.

\footnotetext{
In the present study, the weaker sections are the lower castes (SC/STs), females' gender and rural areas. The 'not literate' and 'lower literate' are also a part of the weaker section of the Indian society, but they dominate the manufacturing sector jobs, so we do not consider them as 'weaker sections' in this study.
} 
Amirapu, A., \& Subramanian, A. (2015). Manufacturing or Services? An Indian Illustration of a Development Dilemma (SSRN Scholarly Paper ID 2623158). Social Science Research Network. https://papers.ssrn.com/abstract=2623158

Araujo, C. (2004). Can Non-Agricultural Employment Reduce Rural Poverty? Evidence from Mexico. Cuadernos de Economía, 41, 383-399. http://www. scielo.cl/scielo.php?pid=S071768212004012400004\&script=sci_arttext\&tlng=pt

Baah-Boateng, W. (2016), The Youth Unemployment Challenge in Africa: What Are the Drivers? The Economic and Labour Relations Review, 27, 413-431.

Bairwa, A.K., Chakradhar, J. and Sharma, P. (2019), Employment Discrimination in Indian Manufacturing Industries: A Logistic Analysis, The Singapore Economic Review, p. S021759081944003X.

Bairwa, A.K., and Sharma, P. (2019a), Impact of Labour Attributes and Probability of Employability in Indian Labour Market: A Sectoral Analysis. Journal of Public Affairs, 19, 1-10.

Bairwa, A.K. and Sharma, P. (2019b), Inter-regional Occupational Disparities in Indian Manufacturing Sector With Regards To Socioeconomic Labour Attributes, Labour \& Industry. A Journal of the Social and Economic Relations of Work, 29, 352-369.

Banerjee, T. (2016), Impacts of Vocational Education and Training on Employment and Wages in Indian Manufacturing Industries: Variation across Social Groups-Empirical Evidences from the 68th Round NSSO Data. The Indian Journal of Labour Economics, 59, 489-509.

Cameron, A.C. and Trivedi, P.K. (2010), Microeconometrics Using Stata, Revised Edition, StataCorp LP, Texas, available at: https://ideas.repec.org/b/tsj/spbook/ musr.html (accessed 3 May 2019).

Cappellari, L. and Tatsiramos, K. (2015), With A Little Help from My Friends? Quality of Social Networks, Job Finding and Job Match Quality. European Economic Review, 78, 55-75.

Das, D. K., \& Kalita, G. (2009). Are Labour-Intensive Industries Generating Employment in India? Evidence from Firm Level Survey. The Indian Journal of Labour Economics, 52, 411. http://www.isleijle.org/ijle/IssuePdf/38d48da48e5c-4f3d-a7d4-432c4abdd190.pdf

Deshpande, A. and Newman, K. (2007), Where the Path Leads: The Role of Caste in Post-University Employment Expectations, Economic and Political Weekly, 42, 4133-4140.

DFID. (2012). Building Jobs and Prosperity in Developing countries. Department for International Development.

Dholakia, R.H. (1994), Spatial dimension of acceleration of economic growth in India, Economic and Political Weekly, 29, 2303-2309.

Dom, H. (1999), Oh You Hindu... AWAKE!, Dalitstan Journal, available at: http:// web.archive.org/web/20011211182139/www.dalitstan.or g/books/index.html.

Fan, C.C. and Sun, M. (2008), Regional Inequality in China, 1978-2006, Eurasian Geography and Economics, 49, 1-18.

FICCI. (2014). Suggested LABOUR POLICY REFORMS. http://ficci.in/ SEDocument/20301/FICCI-NOTE-ON-LABOUR-POLICY-REFORMS.pdf

Gang, I.N., Sen, K. and Yun, M.-S. (2012), Is Caste Destiny? Occupational Diversification Among Dalits in Rural India, SSRN Scholarly Paper No. ID 
1984645, Social Science Research Network, Rochester, NY, available at: https:// papers.ssrn.com/abstract=1984645 (accessed 15 May 2018).

Goldar, B., \& Sadhukhan, A. (2015). Employment and Wages in Indian Manufacturing: Post-reform Performance. International Labour Organization. http://econpapers.repec.org/RePEc:ilo:ilowps:488132

Hout, M. and Rosen, H.S. (1999), Self-Employment, Family Background, and Race, Working Paper No. 7344, National Bureau of Economic Research, available at: https://doi.org/10.3386/w7344.

IHD (Ed.). (2014), India Labour and Employment Report, 2014: Workers in the Era of Globalization, Academic Foundation : Institute for Human Development, New Delhi.

Ilaiah, K. (1996), Why I Am Not a Hindu: A Sudra Critique of Hindutva, Philosophy, Culture, and Political Economy, Distributed by Bhatkal Books International, Bombay.

ILO. (2019), Employment by Economic Activity, available at: https://www.ilo.org/ ilostat-files/Documents/description_ECO_EN.pdf (accessed 14 January 2019).

Kingdon, G.G. (1998), Does the labour market explain lower female schooling in India? Journal of Development Studies, 35, 39-65.

Kong, J. (2011), Factors Affecting Employment, Unemployment, and Graduate Study for University Graduates in Beijing, Advances in Applied Economics, Business and Development, Vol. 1, presented at the International Conference on Advances in Education and Management, Springer Berlin Heidelberg, Dalian, China, 353-361.

Labour Bureau. (2015). Indian Labour Year Book-2011 and 2012. Ministry of Labour and Employment, Government of India.

Labour Bureau. (2016). Fifth Annual Employment-Unemployment Survey (201516) (No. 1). Ministry of Labour and Employment, Government of India. http:// labourbureaunew.gov.in/UserContent/EUS_5th_1.pdf

Maddala, G.S. and Lahiri, K. (2009), Introduction to Econometrics, 4th ed., WileyINDIA, available at: www.wileyeurope.com/college/maddala.

Madheswaran, S. and Attewell, P. (2007), Caste Discrimination in the Indian Urban Labour Market: Evidence from the National Sample Survey, Economic and Political Weekly, 42, 4146-4153.

Marelli, E. and Vakulenko, E. (2016), Youth Unemployment in Italy and Russia: Aggregate Trends and Individual Determinants, The Economic and Labour Relations Review, 27, 387-405.

MOSPI. (2008), NIC 2008 Codes \& Its Description, available at: http://mospi.nic.in/ sites/default/files/6ec_dirEst/ec6_nic_2008_code.html.

Nilsson, S. and Rubenson, K. (2014), On the Determinants of Employment-Related Organised Education and Informal Learning, Studies in Continuing Education, 36, 304-321.

Oxford. (2011). The Global Diversity Report (An Annual Guide to Measure Global Employee Diversity). Oxford Economics.

Panagariya, A. (2008), India: The Emerging Giant, Oxford Univ. Press, Oxford, available at: http://dlx.b-ok.org/ genesis/355000/189cfd89dd3a0b5fac9cf7f27d8f1fe3/_as/\%5BArvind_ Panagariya\%5D_India_The_Emerging_Giant(b-ok.org).pdf. 
Papola, T. S. (2008). Employment Challenge and Strategies in India: An Assessment in the Framework of ILO's Global Employment Agenda. International Labour Organization, Sub-regional Office for South Asia.

Ramaswamy, K. V. (2012). Wage Inequality in Indian Manufacturing: Is It Trade, Technology or Labour Regulations?

Ramaswamy, K.V. (2014). Small Enterprises in Indian Manufacturing and Inclusive Growth: Search for Compensatory Mechanisms, Indira Gandhi Institute of Development Research, Mumbai, available at: http://www.igidr.ac.in/pdf/ publication/WP-2014-018.pdf.

Rani, U., \& Unni, J. (2004). Unorganised and Organised Manufacturing in India: Potential for Employment Generating Growth. Economic and Political Weekly, 4568-4580. http://www.jstor.org/stable/4415652

Schioppa, F.K.P. and Lupi, C. (2002). Family Income and Wealth, Youth Unemployment and Active Labour Market Policies. International Review of Applied Economics, 16, 407-416.

Schmidt, P. and Strauss, R.P. (1975). The Prediction of Occupation Using Multiple Logit Models. International Economic Review, 16, 471.

Sharma, N. (2013). Growth and Structural Change in Indian Manufacturing Since Liberalisation: An Interstate Analysis (Discussion Paper No. 6). Centre for Development Economics and Innovation Studies (CDEIS) Punjabi University. http://www.punjabiuniversity.ac.in/cdeiswebsite/downloads/discussion_ papers/6\%20niharika\%20sharma.pdf

Thurik, A.R., Audretsch, D.B. and others. (1999), Innovation, Industry Evolution and Employment, available at: http://dare.ubvu.vu.nl/handle/1871/48020 (accessed 3 January 2017).

Thorat, S., \& Madheswaran, S. (2018). Graded Caste Inequality and Poverty: Evidence on Role of Economic Discrimination. Journal of Social Inclusion Studies, 4, 3-29. https://doi.org/10.1177/2394481118775873

Walters, V. (2019), Parenting from the 'Polluted' Margins: Stigma, Education and Social (Im) Mobility for the Children of India's Out-Casted Sanitation Workers, South Asia. Journal of South Asian Studies, 1-18.

Wooldridge, J.M. (2003), Introductory Econometrics: A Modern Approach, Economic Analysis, available at:https://doi.org/10.1198/jasa.2006.s154. 


\section{Appendix A}

\section{Table A.}

\section{Variable Description for the Logit Estimation.}

This table reports variable names and their detailed description employed in the logit estimation. The data is taken from fourth (2013-14) and fifth (2015-16) round of the EUS (Employment and Unemployment Survey), Government of India. Panel A provides the details of dependent variable: Manufacturing employment. It is a dichotomous variable in nature, whereby individuals employed in the manufacturing sector are assigned a value of one, otherwise zero. In panel B, we report independent variables employed in logit estimation, namely, sex, location, caste, and education.

\begin{tabular}{lcc}
\hline Variable Name & Dummies & Definition \\
\hline Employment & Panel A: Dependent variable \\
\hline Sex & Panufacturing employment & $\begin{array}{c}1 \text { if person is employed in manufacturing sector, } 0 \\
\text { otherwise (unemployed people are excluded) }\end{array}$ \\
\hline Location & Male & 1 if male, 0 female \\
Faste & Female & 1 if female, 0 male \\
& Rural & 1 if rural, 0 urban \\
& Urban & 1 if urban, 0 rural \\
Education & ST & 1 if SC, 0 otherwise \\
& OBC & 1 if ST, 0 otherwise \\
& Other & 1 if OBC, 0 otherwise \\
Illiterate & 1 if Other, 0 otherwise \\
Below primary & 1 if illiterate, 0 otherwise \\
Primary & 1 if below primary, 0 otherwise \\
& Upper primary & 1 if primary, 0 otherwise \\
Secondary & 1 if upper primary, 0 otherwise \\
Senior secondary & 1 if secondary, 0 otherwise \\
Graduation & 1 if senior secondary, 0 otherwise \\
Above graduation & 1 if graduation, 0 otherwise \\
\end{tabular}


Table B.

\section{Abbreviation of the Selected States.}

This table reports the names of the states and abbreviation thereof. This table provides the sample states used in the regression analysis.

\begin{tabular}{lc}
\hline Name & Abbreviation \\
\hline Andhra Pradesh & AP \\
Arunachal Pradesh & AR \\
Assam & AS \\
Bihar & BH \\
Chattisgarh & CH \\
Gujarat & GJ \\
Goa & GO \\
Himachal Pradesh & HP \\
Haryana & HR \\
Jharkhand & JH \\
Jammu \& Kashmir & JK \\
Karnataka & KA \\
Kerala & KL \\
Meghalaya & MG \\
Maharastra & MH \\
Manipur & MN \\
Madhya Pradesh & MP \\
Mizoram & MZ \\
Nagaland & NG \\
Orissa & OR \\
Punjab & PB \\
Rajasthan & RJ \\
Sikkim & SK \\
Telangana & TL \\
Tamil Nadu & TN \\
Tripura & TR \\
Uttar Pradesh & UP \\
Uttaranchal & UT \\
West Bengal & WB \\
India & IND \\
\hline &
\end{tabular}

